\title{
On the cover of this issue: "Solid Cylinder Torsion for Large Shear Deformation and Failure of Engineering Materials" by W-Y. Lu et al.
}

Published online: 22 January 2021

(C) Society for Experimental Mechanics 2021

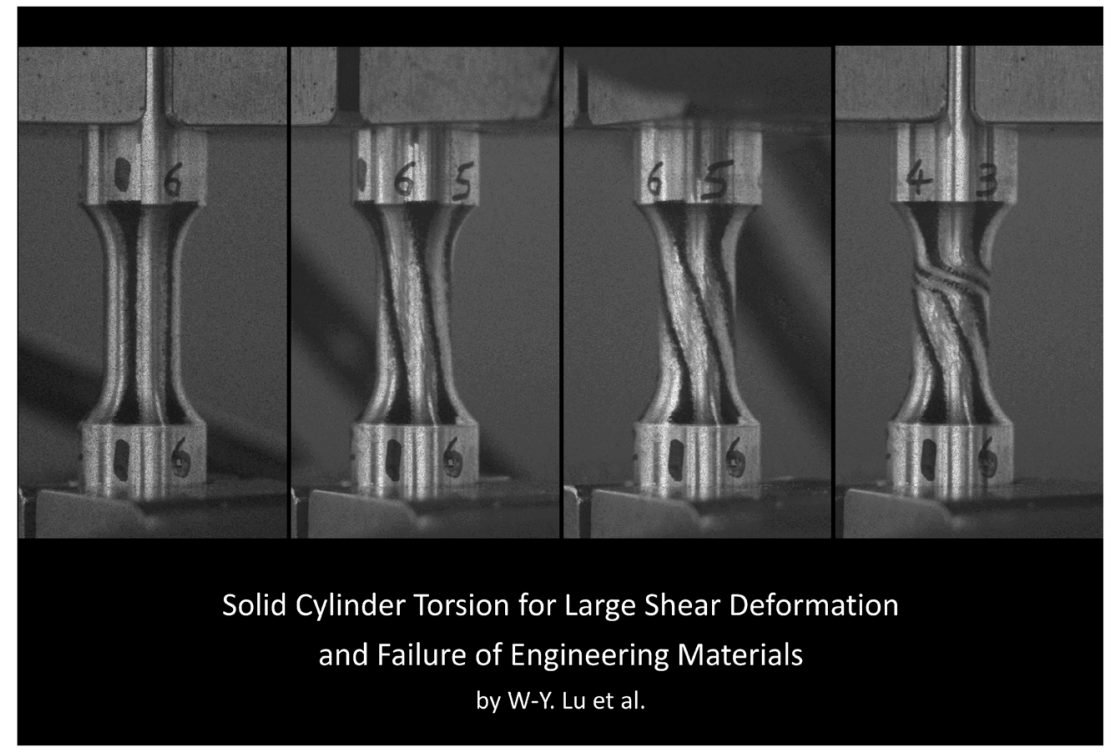

Publisher's Note Springer Nature remains neutral with regard to jurisdictional claims in published maps and institutional affiliations. 